\title{
Self-efficacy beliefs and expectations during an Emergency Medicine Clerkship
}

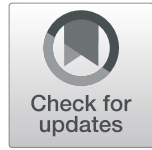

Arif Alper Cevik ${ }^{1,2^{*}} \mathbb{D}$, Elif Dilek Cakal ${ }^{3}$, David Alao ${ }^{1,2}$, Margret Elzubeir ${ }^{4}$, Sami Shaban $^{4}$ and Fikri Abu-Zidan ${ }^{5}$

\begin{abstract}
Background: Undergraduate emergency medicine (EM) training is important because all medical graduates are expected to have basic emergency knowledge and skills regardless of their future speciality. EM clerkship should provide opportunities to improve not only knowledge and skills but also the self-efficacy of learners. This study aims to evaluate the expectations, opinions, and self-efficacy beliefs of medical students during a 4-week mandatory EM clerkship.

Methods: This study used a prospective longitudinal design with quantitative and qualitative survey methods. It includes final year medical students of the 2015-2016 academic year. Voluntary de-identified pre- and postclerkship surveys included 25 statements. The post-clerkship survey included two open-ended questions asking participants to identify the best and worst three aspects of EM clerkship. Responses were analysed to determine themes or commonalities in participant comments indicative of the EM clerkship learning experiences and environment.
\end{abstract}

Results: Sixty-seven out of seventy-nine (85\%) students responded to both pre- and post-clerkship surveys. Medical students' expectations of EM clerkships' effect on knowledge and skill acquisition were high, and a 4-week mandatory EM clerkship was able to meet their expectations. Medical students had very high expectations of EM clerkships' educational environment. In most aspects, their experiences significantly exceeded their expectations ( $p$ value $<0.001)$. The only exception was the duration of clerkship, which was deemed insufficient both at the beginning and at the end ( $p$ value: 0.92 ). The students perceived that their self-efficacy improved significantly in the majority of basic EM skills and procedures ( $p$ value $<0.001$ ). Emergent qualitative themes in the study also supported these results.

Conclusion: This study showed that a 4-week mandatory EM clerkship increased medical students' perceived selfefficacy in basic emergency management skills. The EM clerkship met students' expectations on knowledge and skill acquisition, and exceeded students' expectations on educational environment.

Keywords: Self-efficacy, Medical student, Emergency medicine, Clerkship, Educational environment

\footnotetext{
* Correspondence: aacevik@uaeu.ac.ae

'Department of Internal Medicine, Emergency Medicine Section, College of Medicine and Health Sciences, Al-Ain, United Arab Emirates

${ }^{2}$ Department of Emergency Medicine, Tawam Hospital, Al-Ain, United Arab Emirates

Full list of author information is available at the end of the article
}

(c) The Author(s). 2022 Open Access This article is licensed under a Creative Commons Attribution 4.0 International License, which permits use, sharing, adaptation, distribution and reproduction in any medium or format, as long as you give appropriate credit to the original author(s) and the source, provide a link to the Creative Commons licence, and indicate if changes were made. The images or other third party material in this article are included in the article's Creative Commons licence, unless indicated otherwise in a credit line to the material. If material is not included in the article's Creative Commons licence and your intended use is not permitted by statutory regulation or exceeds the permitted use, you will need to obtain permission directly from the copyright holder. To view a copy of this licence, visit http://creativecommons.org/licenses/by/4.0/ The Creative Commons Public Domain Dedication waiver (http://creativecommons.org/publicdomain/zero/1.0/) applies to the data made available in this article, unless otherwise stated in a credit line to the data. 


\section{Introduction}

Undergraduate emergency medicine (EM) training is important because all medical graduates, regardless of their future speciality, are likely to have to deal with unexpected emergencies at some point in their careers. In addition to their professional duties in the hospital, medical graduates in many countries have an ethical obligation to provide medical care if they encounter out-of-hospital emergencies $[1,2]$. Furthermore, in some contexts, medical graduates practice as independent acute care physicians without further residency training [3]. Therefore, at the end of their undergraduate training, medical students must be knowledgeable and confident about basic acute care management.

To improve medical students' acute care management skills and confidence, EM clerkships, where medical students are exposed to unique acute care encounters, are essential components of medical school curricula $[4,5]$. However, currently, there is a lack of consensus on ideal EM clerkship design, including the duration and content [6-11]. To be able to adjust EM clerkships according to learners' needs, we must measure its effects on trainees. The majority of published works have focused on measuring knowledge and skill acquisition, with very few addressing the issues of educational environment expectations and confidence of medical students on certain aspects of emergency care. Therefore, more studies regarding trainees' educational environment expectations and confidence are required to create optimal clerkships.

Self-efficacy, a central concept of social cognitive theory, refers to an individual's self-belief or self-confidence in performing a specific task to attain a certain standard $[12,13]$. The level of self-efficacy determines the goals that the learner chooses, the level of commitment to learning, willingness to face challenges, resilience, and achievements [12]. Therefore, training should provide opportunities to improve not only knowledge and skills but also the self-efficacy of learners. Self-efficacy can be improved by previous successful attempts and witnessing role models' or peers' successful performances in a safe and encouraging learning environment [14]. A clinical clerkship should improve trainees' self-efficacy in addition to knowledge and skills to be considered effective.

EM clerkships can provide learning opportunities in various learning environments ranging from classroombased learning to authentic clinical experience, which are necessary tools for increased self-efficacy. However, the interplay among multiple influences on self-efficacy, including intrapersonal influences and environmental forces, affects self-efficacy development [15, 16]. Vicarious experiences such as observing someone similar to oneself succeed at a task in a particular learning environment can increase self-efficacy [17]. Negative expectations of a learning environment may intensify anxiety and stress, while positive experiences and expectations may heighten motivation and self-efficacy beliefs. Closely related to self-efficacy beliefs are expectancyvalue and expectancy theory of motivation [18, 19], which posits that individuals' actions are related to their expectations, valuations, perceptions, and desire for continued growth, explaining how motivation is influenced by the expectancy of how well individuals will perform a task or activity. In this sense, students' expectations and opinions about the EM clerkship are as relevant to selfefficacy as vicarious and hands-on learning opportunities provided by the clerkship.

This study aims to evaluate the expectations, opinions and self-efficacy beliefs of medical students during a 4week mandatory EM clerkship and has two research questions: (1) to what extent can an EM clerkship meet students' expectations regarding knowledge and skill acquisition, and educational environment? and (2) to what extent can an EM clerkship increase medical students' self-efficacy in basic emergency skills?

\section{Materials and methods \\ Ethical approval}

This study is approved by The United Arab Emirates University (UAEU) Research and Graduate Studies Ethics Committee (ERS_2017_5496).

\section{Study setting and participants}

This study was based on the EM clerkship experience of the 2015-2016 final year medical students of the College of Medicine and Health Sciences, UAEU, Al Ain, United Arab Emirates [20].

The medical education department establishes the student groups at the beginning of each academic year. For the 2015-2016 academic year, there were three female and two male student groups. Each group has 12 to 19 students. The groups rotate through the five senior clinical clerkships of EM (4 weeks), family medicine (4 weeks), pediatrics ( 8 weeks), internal medicine (8 weeks), and surgery ( 8 weeks).

\section{EM clerkship design}

Our EM clerkship is 4 weeks long and is undertaken during the final (sixth) year of medical school. The clerkship's teaching and learning activities are designed according to international undergraduate curriculum recommendations $[6,21]$. In addition to teaching sessions in the classroom and simulation centre, students participate in clinical shifts under the supervision of residency-trained emergency physicians and residents in two medical school-affiliated community teaching hospitals. In total, the emergency departments of both 
hospitals treat over 200,000 patients annually (Tawam Hospital ED treats approximately $105,000-110,000$ patients, and $\mathrm{Al}$ Ain Hospital ED treats approximately 110,000-115,000 patients annually). Sundays and Thursdays are reserved for classroom and simulation-based learning respectively while the other days of the week are allocated for clinical shifts. The clerkship includes various formative and summative assessments such as work-based assessments, written tests, Objective Structured Clinical Examination (OSCE), and logbooks for patient and procedure encounters. The details of the EM clerkship curriculum and students' logbooks can be found elsewhere [22, 23].

\section{Study design and data collection}

This study used prospective longitudinal design with quantitative and qualitative survey methods. A previously published survey [10] was adapted to our context. A voluntary de-identified survey was taken on the first day of clerkship (pre-clerkship survey) and the last day of the clerkship (post-clerkship survey). The survey included 25 statements to capture students' pre-clerkship expectations and post-clerkship opinions regarding knowledge and skill acquisition, educational environment, and self-efficacy. Each statement was evaluated using a five-point Likert Scale, from strongly disagree to strongly agree. In addition, a post-clerkship survey included two open-ended questions asking participants to identify the three best and worst aspects of EM clerkship. We did not add any new material or method to the curriculum, and no modifications were made prior to the beginning of the study to impact the students' responses. Responses were analysed to determine themes or commonalities in participant comments indicative of the EM clerkship learning experiences and environment. Each student used a matching code in both surveys to protect students' privacy and avoid the influence of power differentials. The online survey/assessment tool Socrative [24] was used to conduct the surveys. The results were extracted into an excel sheet, cleaned, and prepared for the data analysis.

\section{Data analysis}

To compare students' responses between the preclerkship and post-clerkship surveys, the non-parametric Wilcoxon signed-rank test was used. The internal consistency reliability of the survey was calculated using Cronbach's alpha coefficient. To measure the strength and direction of the association between two variables, Spearman's rank correlation was used. The Statistical Package for the Social Sciences (IBM-SPSS version 26, Chicago, IL) was used for quantitative analysis. Statistical significance is accepted at a level less than 0.05 of $p$ value. Two of the authors manually analysed the qualitative data for congruence and faithful representation of emerging themes..

\section{Results}

Seventy-nine final year medical students attended a 4week mandatory EM clerkship during the study period of which 54 (68\%) were female and 25 (32\%) were male. The number of students in each of the five groups ranged from 12 to 19 . Sixty-seven students (85\%) responded to both pre-clerkship and post-clerkship surveys and were included in the analysis. A Cronbach's alpha of 0.89 was observed for the pre-clerkship survey, indicating good internal consistency of this survey.

Table 1 shows pre-clerkship scores of expectations and post-clerkship scores of opinions. Regarding perceived knowledge and skill acquisition, the means of all preclerkship scores were above 4 (agree), which shows high expectations from the clerkship at the beginning. Postclerkship mean scores did not change significantly (Wilcoxon signed ranks test, $p$ value: 0.33 ). Students' scores on the educational environment of EM clerkship improved significantly (Wilcoxon signed ranks test, $p$ value $<0.001$ ). However, students' scores on the appropriateness of the EM clerkship duration did not change after the clerkship (Wilcoxon signed ranks test, $p$ value: 0.92 ).

Table 2 shows pre- and post-clerkship scores of perceived self-efficacy in specific patient management and procedural skills. The overall change was significant (Wilcoxon Signed Ranks test, $p$ value $<0.001$ ). After the clerkship, students' scores improved significantly in eight out of 13 statements. The scores for formulating a differential diagnosis list, developing an appropriate management plan, inserting a Foley catheter and inserting IV cannula/venipuncture were improved but did not show a significant change.

The students' pre-clerkship scores of perceived knowledge and skill acquisition were moderately correlated with pre-clerkship scores of perceived self-efficacy (Spearman's Rho 0.53, $p$ value $<0.001$ ). Pre-clerkship scores of educational environment showed a weak correlation with pre-clerkship scores of perceived selfefficacy (Spearman's rho 0.27, $p$ value 0.03 ).

The students' post-clerkship scores of perceived knowledge and skill acquisition showed a strong correlation with post-clerkship scores of perceived self-efficacy (Spearman's rho 0.70, $p$ value $<0.001$ ). Post-clerkship scores of educational environment showed moderate correlation with students' post-clerkship scores of perceived self-efficacy (Spearman's rho 0.49, $p$ value $<0.001$ ).

The difference between post- and pre-clerkship scores of knowledge and skills acquisition were moderately correlated with the difference between post- and preclerkship scores of perceived self-efficacy (Spearman's rho $0.47, p$ value $<0.001)$. The difference between post- 
Table 1 Pre-clerkship scores of expectations and post-clerkship scores of opinions

\begin{tabular}{|c|c|c|c|c|c|}
\hline \multirow[b]{2}{*}{ Category and questions } & \multicolumn{2}{|l|}{ Pre-clerkship scores } & \multicolumn{2}{|l|}{ Post-clerkship scores } & \multirow[b]{2}{*}{$p$ value } \\
\hline & Median (min-max) & Mean (SD) & Median (min-max) & Mean (SD) & \\
\hline $\begin{array}{l}\text { Knowledge and skill acquisition } \\
\text { I believe, in the EM clerkship, I will/did }\end{array}$ & $4.50(3-5)$ & $4.38(0.56)$ & $4.25(2-5)$ & $4.32(0.57)$ & 0.329 \\
\hline Increase my knowledge & $5(1-5)$ & $4.60(0.82)$ & $5(2-5)$ & $4.43(0.66)$ & 0.057 \\
\hline Gain self-confidence to manage emergency cases & $4(2-5)$ & $4.31(0.70)$ & $4(2-5)$ & $4.28(0.67)$ & 0.664 \\
\hline Gain self-confidence to do basic emergency procedures & $4(2-5)$ & $4.22(0.74)$ & $4(2-5)$ & $4.21(0.69)$ & 0.907 \\
\hline Encounter a variety of patients & $4(2-5)$ & $4.37(0.71)$ & $4(2-5)$ & $4.37(0.71)$ & 0.985 \\
\hline Educational environment & $3.6(2.6-4.9)$ & $3.57(0.41)$ & $4(2.9-5)$ & $3.93(0.44)$ & $<0.001$ \\
\hline \multicolumn{6}{|l|}{ I believe, } \\
\hline EM clerkship duration (4 weeks) is appropriate & $2(1-5)$ & $2.43(1.03)$ & $2(1-5)$ & $2.46(1.34)$ & 0.917 \\
\hline Clerkship director is easily reachable & $4(3-5)$ & 4.04(0.71) & $5(3-5)$ & $4.57(0.61)$ & $<0.001$ \\
\hline EM faculty members are easily reachable & $4(2-5)$ & $3.88(0.75)$ & $4(1-5)$ & $4.25(0.84)$ & 0.006 \\
\hline Grading percentages and process are appropriate & $3(2-5)$ & $3.55(0.66)$ & $4(3-5)$ & $3.96(0.75)$ & 0.001 \\
\hline EM clerkship is overall good learning experience & $4(3-5)$ & $4.03(0.63)$ & $4(2-5)$ & $4.40(0.68)$ & $<0.001$ \\
\hline I consider choosing EM as an additional elective rotation & $4(1-5)$ & $3.48(1.06)$ & $4(1-5)$ & 3.96(0.98) & 0.002 \\
\hline I prefer to take additional EM course in early years & $4(1-5)$ & $3.58(1.03)$ & $4(2-5)$ & $3.94(1.03)$ & 0.022 \\
\hline
\end{tabular}

$p$ value Wilcoxon signed ranks test

and pre-clerkship scores of educational environment were moderately correlated with difference between post- and pre-clerkship scores on perceived self-efficacy (Spearman's rho 0.41, $p$ value $<0.001$ ).

In qualitative analysis, emerging themes about positive aspects of EM clerkship included numerous and diverse opportunities for hands-on training including patient encounters and procedures; helpful and supportive program director, and healthcare staff including attending physicians, residents and nurses; an organised and well-structured clerkship; high quality and diversity of teaching methods and materials. Additionally, the students stated that EM clerkship increased knowledge and confidence in patient management and procedures. Their main complaint was the short duration of EM clerkship. In addition, sleep deprivation due to shifts,

Table 2 Pre- and post-clerkship scores of perceived self-efficacy

\begin{tabular}{|c|c|c|c|c|c|}
\hline \multirow[b]{2}{*}{ Category and questions } & \multicolumn{2}{|l|}{ Pre-clerkship scores } & \multicolumn{2}{|l|}{ Post-clerkship scores } & \multirow[b]{2}{*}{$p$ value } \\
\hline & Median (min-max) & Mean (SD) & Median (min-max) & Mean (SD) & \\
\hline \multicolumn{6}{|l|}{ I am able to } \\
\hline Conduct an initial assessment of an acutely ill patient & $4(2-5)$ & $4.04(0.78)$ & $4(3-5)$ & 4.25(0.59) & 0.045 \\
\hline Identify a "sick" vs. "non-sick" patient & $4(2-5)$ & $3.97(0.74)$ & $4(3-5)$ & $4.25(0.53)$ & 0.013 \\
\hline Formulate a differential diagnosis list & $4(3-5)$ & $4.21(0.66)$ & $4(2-5)$ & $4.22(0.62)$ & 0.861 \\
\hline Develop an appropriate management plan & $4(3-5)$ & $3.97(0.67)$ & $4(2-5)$ & $4.07(0.61)$ & 0.312 \\
\hline Present cases in a formal setting & $4(2-5)$ & $3.37(0.94)$ & $4(3-5)$ & $3.73(0.86)$ & 0.019 \\
\hline Perform wound closure and repair & $4(1-5)$ & $3.58(0.92)$ & $4(2-5)$ & $4.04(0.75)$ & 0.003 \\
\hline Insert Foley catheter & $4(1-5)$ & $3.51(0.96)$ & $4(1-5)$ & $3.60(0.94)$ & 0.511 \\
\hline Interpret EKG & $4(1-5)$ & $3.97(0.80)$ & $4(3-5)$ & $4.30(0.70)$ & 0.005 \\
\hline Perform basic life support & $4(2-5)$ & $3.76(0.87)$ & $4(3-5)$ & $4.30(0.60)$ & $<0.001$ \\
\hline Participate medical resuscitation & $3(1-5)$ & $3.21(1.01)$ & $4(3-5)$ & $4.10(0.68)$ & $<0.001$ \\
\hline Participate trauma resuscitation & $3(1-5)$ & $3.15(0.97)$ & $4(3-5)$ & $4.21(0.66)$ & $<0.001$ \\
\hline Perform splinting/fracture care & $3(2-5)$ & $3.31(1.02)$ & $4(1-5)$ & $3.85(0.88)$ & $<0.001$ \\
\hline Place an IV access/venipuncture & $4(3-5)$ & $4.07(0.75)$ & $4(3-5)$ & $4.27(0.67)$ & 0.121 \\
\hline Place a NG tube & $4(2-5)$ & $3.78(0.85)$ & $4(1-5)$ & $3.51(0.91)$ & 0.058 \\
\hline Overall & $3.71(2.3-5)$ & $3.75(0.58)$ & $4(2.9-5)$ & $4.08(0.48)$ & $<0.001$ \\
\hline
\end{tabular}

$p$ value Wilcoxon signed ranks test 
difficulty filling logbook due to computer-based systems, and the suboptimal attitude of some healthcare staff were emerging themes. Also, students stated that they wished to receive additional EM training in the early years of medical school.

\section{Discussion}

Our results showed that medical students' expectations on knowledge and skill acquisition were high and a 4week mandatory EM clerkship was able to meet expectations. Similarly, they had very high expectations on educational environment. In most aspects of the educational environment, their experience exceeded their expectation significantly. The only exception was the duration of clerkship, which was deemed insufficient both at the beginning and at the end. The students perceived that their self-efficacy in the majority of basic skills and procedures improved significantly. These results were also supported by emergent qualitative themes in the study.

Medical students' expectations of EM clerkships are affected by many factors. EM's popularity by mainstream and social media, students' previous exposure to emergency departments, and previous students' positive experiences with EM clerkship may affect students' expectations [25-27]. In our setting, students' expectations of EM clerkship regarding knowledge and skill acquisition were quite high. The high expectation from EM clerkships has been well documented in the literature [27]. Because of such high expectations, it may not always be possible to observe a significant increase in scores after the clerkship. Even if the post-clerkship scores were not increased in our study, they remained stable, which may show that the EM clerkship met students' expectations. Inclusion of students' expectations of learning environment provides insight into a potential building block to students' self-efficacy. Perceptions of a structured, supportive learning environment, involvement in a variety of patient encounters and procedures and role modelling by multidisciplinary team members, observed in our study, enhanced positive expectations of the utility of the learning experience which in turn supported self-efficacy.

The implementation of EM clerkships in medical school curricula vary significantly. In the United States, a pioneer in EM training, the percentage of medical schools implementing mandatory EM clerkships was only $52 \%$ as of 2014 [28]. In addition, when to implement EM clerkship in medical school curriculum is controversial $[28,29]$. Despite the suggested ideal duration of at least 4 weeks, the duration of EM clerkships varies among countries, ranging from 1 to 6 weeks [7, 30-32]. Even in a mature system, at least $18 \%$ of EM clerkships remained shorter than 4 weeks [28]. We have implemented a 4-week mandatory EM clerkship in the final year of a 6-year medical school program since 2013 [22]. Though our students' perceived self-efficacy was increased significantly during 4 weeks and the duration of our EM clerkship is aligned with the recommendations, our results showed that students deemed 4 weeks of emergency medicine clerkship too short. Also, they seem to prefer taking additional EM training in earlier years.

EM clerkship provides an excellent opportunity for medical students to practice fundamental topics and procedures and facilitates knowledge acquisition and self-efficacy in basic procedures and patient management skills [33-35]. Similar to reports by Avegno et al. [10] our medical students stated high self-efficacy values at the beginning of the EM clerkship with significantly increased values on 8 of 13 items. The items with the greatest perceived self-efficacy change were the items that are mostly exclusive to emergency departments, such as basic life support, medical, and trauma resuscitations.

There are several ways to boost the self-efficacy of a learner. Previous successes, performed by self or observations of others, raise self-efficacy, while failures lower it [14]. In our EM clerkship, medical students have opportunities for supervised skills and procedures, which are tailored to their levels, and opportunities for observing peers' performances [22, 23]. A supportive educational environment is also essential for self-efficacy and effective learning [36, 37]. In our study, the medical students' pre-clerkship scores of elements measuring the educational environment were high at the beginning and significantly increased at the end. Similar to previous reports, our students valued the variety of cases seen, opportunities to develop clinical skills, teachers' support and commitment to learning, close supervision, and the ability to reach teachers when needed [38-40]. We note that their positive perception of the educational environment may have contributed to increasing self-efficacy, as ultimately, the greater the expectations of the learning environment are met, the greater the potential for a perceived sense of control and self-efficacy.

Self-efficacy is associated with motivation, which greatly facilitates learning. In undergraduate medical education, a higher level of motivation increases academic success and performance [41]. The motivational dynamic model suggests that self-efficacy is a key determinant of motivation to learn [42]. Therefore, medical teachers should promote motivation during teaching and learning activities. In our study, students' increased interest in additional EM training suggests that their motivation to learn EM had increased with their selfefficacy.

In addition to its relation to motivation and expectancy beliefs, self-efficacy has a sophisticated relation to performance [43]. Mavis [44] examined the relationship 
between several constructs, including self-efficacy and OSCE score. He found that although there was no overall correlation between self-efficacy and OSCE score, the students with high self-efficacy performed significantly better at OSCE than students with low self-efficacy. Based on the correlations between constructs, he created a framework which suggests that an increase in biomedical knowledge and clinical skills improve self-efficacy by decreasing anxiety, and self-efficacy promotes performance by increasing preparedness [44]. Self-efficacy seems to contribute to performance but not exclusively; personal attributes also apply [45]. Conversely, self-efficacy not rooted in reality might hinder performance because it makes novice learners more prone to errors [46]. In our study, we compared self-efficacy with students' perceptions of knowledge and skill acquisition rather than objective assessment scores. Students' perceptions of knowledge and skill acquisition seemed correlated with self-efficacy; however, students' self-evaluated performance may not always reflect objective assessment scores. Also, the correlation post-clerkship self-efficacy and post-clerkship perceptions on learning environment may be due to overlap among these constructs. Bandura [15, 16] also included expectancies in his discussion of selfefficacy development. Understanding effect sizes of related constructs could be an important contribution to the study of these variables in medical education [43]. Recognising the impact of perceptions and expectations of the learning environment on self-efficacy beliefs could be helpful in the development of EM clerkship curricula, and identif and support students at risk. Educators may increase knowledge acquisition by promoting selfefficacy. Self-efficacy boosts motivation, and motivation may lead to knowledge increase, creating a beneficial cycle.

\section{Limitations}

There are some limitations in our study. First, this was a single-center study conducted over one academic year having a small sample size. Second, there was no control group to compare the effect of mandatory versus elective clerkships, different clerkship durations and different EM clerkship years. Third, we did not use a previously validated self-efficacy scale, which may provide more structured and objective information $[47,48]$. Cognizant that there is no single all-purpose measure of selfefficacy, since the construct is not a generalised trait and people differ in efficacy across different domains, we constructed a scale based on sound conceptual determinants of self-efficacy in an undergraduate task-related EM domain. Fourth, we did not compare OSCE and written assessment scores with students' self-efficacy belief scores, which could give additional information regarding students' actual gain in the clerkship. Instead, we measured subjective expectations and opinions on knowledge and skills acquisition, and educational environment. Fifth, the clerkship is modelled after international undergraduate curriculum recommendations, which may differ from the curricula used at other institutions, limiting the generalisability of the study. Finally, we acknowledge there is scope for longitudinal research, evaluating a broader set of related constructs and changes in self-efficacy.

\section{Conclusions}

This study has shown that a 4-week mandatory EM clerkship increased medical students' perceived selfefficacy in basic emergency management and skills. It also met students' expectations on knowledge and skill acquisition and exceeded students' expectations on the educational environment. Considering their contributions to learning, motivation, and performance, selfefficacy and expectations of educational environment and activities are valuable factors in developing and measuring EM clerkships. Future studies could focus on how changes to the curricula could affect self-efficacy beliefs and could also look at whether there is a correlation between self-efficacy beliefs and performance by comparing the self-efficacy scores of students to OSCE, work-based assessments, or written test scores.

\section{Authors' contributions \\ $A A C, E D C$, and FAZ created the research question. AAC conceived the study, designed the trial, and supervised the conduct of the trial and data collection. EDC provided reference searches and collated available information in the literature. FAZ provided statistical advice on study design, and $A A C$ and FAZ analyzed the data. AAC, EDC, DA, MEZ, SS, and FAZ drafted the manuscript, and all authors contributed substantially to its revision. AAC takes responsibility for the paper as a whole. All authors read and approved the final manuscript.}

\section{Funding}

No financial support was used for the study.

\section{Declarations}

Competing interests

AAC, EDC, DA, MEZ, SS, and FAZ report no conflict of interest.

\section{Author details}

${ }^{1}$ Department of Internal Medicine, Emergency Medicine Section, College of Medicine and Health Sciences, Al-Ain, United Arab Emirates. ${ }^{2}$ Department of Emergency Medicine, Tawam Hospital, Al-Ain, United Arab Emirates. ${ }^{3}$ Masters of Medical Education, University of Dundee, Dundee, UK. ${ }^{4}$ Department of Medical Education, College of Medicine and Health Sciences, United Arab Emirates University, Al-Ain, United Arab Emirates. ${ }^{5}$ Department of Surgery, College of Medicine and Health Sciences, United Arab Emirates University, Al-Ain, United Arab Emirates.

Received: 4 May 2021 Accepted: 27 December 2021

Published online: 22 January 2022

\section{References}

1. Macy J Jr. The role of emergency medicine in the future of American medical care. Annals of emergency medicine. 1995;25(2):230-3. https://doi. org/10.1016/s0196-0644(95)70329-2. 
2. Manthey DE, Coates WC, Ander DS, Ankel FK, Blumstein H, Christopher TA, et al. Report of the Task Force on National Fourth Year Medical Student Emergency Medicine Curriculum Guide. Ann Emerg Med. 2006;47(3):e1-7. https://doi.org/10.1016/..annemergmed.2005.09.002.

3. Cevik AA, Rodoplu U, Holliman CJ. Update on the development of emergency medicine as a specialty in Turkey. Eur J Emerg Med: Off J Eur Soc Emerg Med. 2001;8(2):123-9. https://doi.org/10.1097/00063110-2001 06000-00008.

4. Garmel GM, Pettis HM, Lane DR, Darvish A, Winters M, Vallee $P$, et al. Clerkships in Emergency Medicine. J Emerg Med. 2020;58(4):e215-22. https://doi.org/10.1016/j.jemermed.2019.11.024.

5. Liaison Committee for Medical Education. Functions and Structure of a Medical School. Standards for Accreditation of Medical Education Programs Leading to the MD Degree. [cited 2020 May 20] https://www. lcme.org.

6. Hobgood C, Anantharaman V, Bandiera G, Cameron P, Halpern P, Holliman $\mathrm{CJ}$, et al. International Federation for Emergency Medicine model curriculum for medical student education in emergency medicine. Int J Emerg Med. 2010:3(1):1-7. https://doi.org/10.1007/s12245-009-0142-7.

7. Wai AKC, Graham CA, Rainer TH. Undergraduate emergency medicine training: past, present and future. Hong Kong J Emerg Med. 2006;13(3):17884. https://doi.org/10.1177/102490790601300310.

8. Cameron P, Hobgood C, Mulligan T. Developments in international emergency medicine. Emerg Med Australas: EMA. 2009;21(5):339-41. https:// doi.org/10.1111/j.1742-6723.2009.01211.x.

9. Hodkinson PW, Wallis LA. Emergency medicine in the developing world: a Delphi study. Acad Emerg Med: Off J Soc Acad Emerg Med. 2010;17(7):76574. https://doi.org/10.1111/j.1553-2712.2010.00791.x.

10. Avegno JL, Murphy-Lavoie H, Lofaso DP, Moreno-Walton L. Medical students' perceptions of an emergency medicine clerkship: an analysis of self-assessment surveys. Int J Emerg Med. 2012;5(1):25. https://doi.org/10.11 86/1865-1380-5-25.

11. Wald DA, Manthey DE, Kruus L, Tripp M, Barrett J, Amoroso B. The state of the clerkship: a survey of emergency medicine clerkship directors. Acad Emerg Med: Off J Soc Acad Emerg Med. 2007;14(7):629-34. https://doi.org/1 0.1197/j.aem.2007.02.035

12. Bandura A. Perceived self-efficacy in cognitive development and functioning. Educ Psychol. 1993;28(2):117-48. https://doi.org/10.1207/s1532 6985ep2802_3.

13. Kaufman DM, Mann KV. Teaching and learning in medical education: how theory can inform practice. In: Swanwick T, editor. Understanding Medical Education: Evidence, Theory and Practice. 2nd ed. Oxford: Wiley Blackwell, P7-29; 2014. p. 7-30

14. Bandura A. Self-efficacy: toward a unifying theory of behavioral change. Psychol Rev. 1977;84(2):191-215. https://doi.org/10.1037//0033-295x.84.2.191.

15. Bandura A. Self-efficacy: The exercise of control. New York: W.H. Freeman and Company; 1997.

16. Bandura A. On the functional properties of perceived Self-Efficacy revisited. J Manag. 2012;38(1):9-44. https://doi.org/10.1177/0149206311410606.

17. Schunk DH, Hanson AR. Influence of peer-model attributes on children's beliefs and learning. J Educ Psychol. 1989;81(3):431-4. https://doi.org/10.103 7/0022-0663.81.3.431.

18. Vroom VH. Work and motivation. Oxford, England: Wiley; 1964.

19. Wigfield A, Eccles JS. Expectancy-Value Theory of Achievement Motivation. Contemp Educ Psychol. 2000;25(1):68-81. https://doi.org/10.1006/ceps.1 999.1015.

20. Cevik AA, Cakal ED, Shaban S, El Zubeir M, Abu-Zidan FM. A mandatory Emergency Medicine clerkship influences students' career choices in a developing system. Afr J Emerg Med. 2021;11(1):70-3. https://doi.org/10.101 6/j.afjem.2020.08.003 Epub 2020 Sep 3. PMID: 33680724; PMCID: PMC7910188.

21. Manthey DE, Ander DS, Gordon DC, Morrissey T, Sherman SC, Smith MD, et al. Emergency medicine clerkship curriculum: an update and revision. Acad Emerg Med: Off J Soc Acad Emerg Med. 2010;17(6):638-43. https://doi. org/10.1111/j.1553-2712.2010.00750.x.

22. Cevik AA, Cakal ED, Abu-Zidan FM. Emergency medicine clerkship curriculum in a high-income developing country: methods for development and application. Int J Emerg Med. 2018;11(1):31. https://doi.org/10.1186/ s12245-018-0190-y.

23. Shaban S, Cevik AA, Canakci ME, Kuas C, El Zubeir M, Abu-Zidan F. Do senior medical students meet recommended emergency medicine curricula requirements? BMC Med Educ. 2018;18(1):8. https://doi.org/10.1186/s12909017-1110-1 PMID: 29304795; PMCID: PMC5756377.

24. Socrative. Showbie Inc. 2011. [cited 2020 July 2] https://socrative.com/

25. Cadogan M, Thoma B, Chan TM, Lin M. Free Open Access Meducation (FOAM): the rise of emergency medicine and critical care blogs and podcasts (2002-2013). Emerg Med J: EMJ. 2014;31(e1):e76-7. https://doi. org/10.1136/emermed-2013-203502.

26. Lamba S, Nagurka R, Holland B, Scott S. Impact of an emergency medicine clerkship on students' perceptions of emergency medicine. Adv Med Educ Pract. 2015;6:105-12. https://doi.org/10.2147/AMEP.S77037.

27. Penciner R. Emergency medicine preclerkship observerships: evaluation of a structured experience. CJEM. 2009;11(3):235-9. https://doi.org/10.1017/s1481 803500011258 .

28. Khandelwal S, Way DP, Wald DA, Fisher J, Ander DS, Thibodeau L, et al. State of undergraduate education in emergency medicine: a national survey of clerkship directors. Acad Emerg Med: Off J Soc Acad Emerg Med. 2014; 21(1):92-5. https://doi.org/10.1111/acem.12290.

29. Mulcare MR, Suh EH, Tews M, Swan-Sein A, Pandit K. Third-year medical student rotations in emergency medicine: a survey of current practices. Acad Emerg Med: Off J Soc Acad Emerg Med. 2011;18(Suppl 2):S41-7. https://doi.org/10.1111/j.1553-2712.2011.01187.x.

30. American College of Emergency Physicians. Guidelines for undergraduate education in emergency medicine. Ann Emerg Med. 1987;16(1):117-9. https://doi.org/10.1016/s0196-0644(87)80301-3.

31. Shepherd S, Zun L, Mitchell J, Binder L, Emerman C, Green R, et al. A model preclinical, clinical, and graduate educational curriculum in emergency medicine for medical students and rotating residents. Ann Emerg Med. 1990;19(10):1159-66. https://doi.org/10.1016/s0196-0644(05)81522-7.

32. Kim SH, Yang EB, Ahn DS, Jeon WT, Lyu CJ. The present conditions of clinical clerkship management in Korea. Korean J Med Educ. 2009;21(4):37383. https://doi.org/10.3946/kjme.2009.21.4.373.

33. Wald DA, Lin M, Manthey DE, Rogers RL, Zun LS, Christopher T. Emergency medicine in the medical school curriculum. Acad Emerg Med: Off I Soc Acad Emerg Med. 2010;17(Suppl 2):S26-30. https://doi.org/10.1111/j.1553-2 712.2010.00896.x.

34. Goolsby CA, Goodwin TL, Vest RM. Hybrid simulation improves medical student procedural confidence during EM clerkship. Mil Med. 2014;179(11): 1223-7. https://doi.org/10.7205/MILMED-D-14-00072.

35. Saxer T, Duperrex O, Vermeulen B, Vu NV. Emergency medicine training: a prospective, comparative study of an undergraduate clinical clerkship and an army programme. Swiss Med Wkly. 2009;139(29-30):423-9 smw-12691.

36. Bayat B, Salehiniya H. Assessment of condition perception of educational -research environment and academic self-efficacy. J Educ Health Promot. 2018;7:105. https://doi.org/10.4103/jehp.jehp_38_18.

37. Caverzagie KJ, Goldenberg MG, Hall JM. Psychology and learning: The role of the clinical learning environment. Med Teach. 2019;41(4):375-9. https:// doi.org/10.1080/0142159X.2019.1567910.

38. Guth TA, Overbeck MC, Roswell K, Vu TT, Williamson KM, Yi Y, et al. Impact of a Dedicated Teaching Attending Experience on a Required Emergency Medicine Clerkship. West J Emerg Med. 2019;21(1):58-64. https://doi.org/10. 5811/westjem.2019.11.44399.

39. House JB, Griffith MC, Kappy MD, Holman E, Santen SA. Tracking Student Mistreatment Data to Improve the Emergency Medicine Clerkship Learning Environment. West J Emerg Med. 2018;19(1):18-22. https://doi.org/10.5811/ westjem.2017.11.36718.

40. Yeung M, Beecker J, Marks M, Nuth J, Weitzman B, Lee AC, et al. A new emergency medicine clerkship program: students' perceptions of what works. CJEM. 2010;12(3):212-9. https://doi.org/10.1017/s1481803500012264.

41. Kusurkar RA, Ten Cate TJ, van Asperen M, Croiset G. Motivation as an independent and a dependent variable in medical education: a review of the literature. Med Teach. 2011;33(5):e242-62. https://doi.org/10.3109/01421 59X.2011.558539.

42. Pelaccia T, Viau R. Motivation in medical education. Med Teach. 2017;39(2): 136-40. https://doi.org/10.1080/0142159X.2016.1248924.

43. Meyer J, Fleckenstein J, Koller O. Expectancy value interactions and academic achievement: differential relationships with academic measures. Contemp Educ Psychol. 2019;58:58-74. https://doi.org/10.1016/j.cedpsych.2 019.01.006.

44. Mavis B. Self-efficacy and OSCE performance among second year medical students. Adv Health Sci Educ: Theory Pract. 2001;6(2):93-102. https://doi. org/10.1023/a:1011404132508. 
45. Judge TA, Jackson CL, Shaw JC, Scott BA, Rich BL. Self-efficacy and workrelated performance: the integral role of individual differences. J Appl Psychol. 2007:92(1):107-27. https://doi.org/10.1037/0021-9010.92.1.107.

46. Liaw SY, Scherpbier A, Rethans JJ, Klainin-Yobas P. Assessment for simulation learning outcomes: a comparison of knowledge and selfreported confidence with observed clinical performance. Nurse Educ Today. 2012;32(6):e35-9. https://doi.org/10.1016/j.nedt.2011.10.006

47. Artino AR Jr, Dong T, DeZee KJ, Gilliland WR, Waechter DM, Cruess DF, et al. Development and initial validation of a survey to assess students' selfefficacy in medical school. Mil Med. 2012;177(9 Suppl):31-7. https://doi. org/10.7205/milmed-d-12-00240.

48. Van Horn E, Christman J. Assessment of Nursing Student Confidence Using the Clinical Skills Self-Efficacy Scale. Nurs Educ Perspect. 2017;38(6):344-6. https://doi.org/10.1097/01.NEP.0000000000000169.

\section{Publisher's Note}

Springer Nature remains neutral with regard to jurisdictional claims in published maps and institutional affiliations.

Ready to submit your research? Choose BMC and benefit from:

- fast, convenient online submission

- thorough peer review by experienced researchers in your field

- rapid publication on acceptance

- support for research data, including large and complex data types

- gold Open Access which fosters wider collaboration and increased citations

- maximum visibility for your research: over $100 \mathrm{M}$ website views per year

At BMC, research is always in progress.

Learn more biomedcentral.com/submissions 